\title{
Diagnosis, assessments and admissions from a community treatment team
}

\author{
Neil Brimblecombe and Geraldine H. O'Sullivan
}

\begin{abstract}
Aims and method A community treatment team, offering rapid assessment and intensive home treatment as an alternative to admission is described. The relationship between diagnosis and outcome was examined, in terms of initial 'take on' rates, admissions to in-patient areas at both initial assessment and subsequently.

Results There was a significant relationship between diagnosis and outcome, with marked variation between diagnostic categories.

Clinical implications Home treatment teams prevent admissions with the majority of people from all diagnostic groups, but less successfully with people with personality disorder.
\end{abstract}

A significant number of people with severe, acute mental illness can be successfully treated in their own homes. Intensive home-based treatment may produce similar or superior outcomes in symptomatology compared to hospital-focused services (Stein et al, 1975; Hoult et al, 1984; Mujien et al, 1992; Dean et al. 1993).

Increasing pressure on acute admission beds has emphasised the need to offer community alternatives whenever possible to allow inpatient resources to meet the needs of those most at risk (Johnson, 1997). However, research is limited into whether the early results of pioneering services can be replicated when delivered in more normal, everyday practice (Burns et al, 1993).

We report on the patients assessed by a home treatment service in its first full year of operation.

\section{The study}

The Dacorum Community Treatment Team (CTT) offers rapid assessment and intensive home treatment as an alternative to admission. Treatment may involve frequent home visits of up to several times a day, and include assistance with and prescribing of medication, supporting and advising carers, crisis counselling, assistance with activities of daily living or linking in with day care services.

The team is based in a mixed urban and rural setting in Hertfordshire covering a population of 125000 . Staffing consists of nine qualified nurses covering from 9 am to $9 \mathrm{pm}$ seven days a week, with a staff grade psychiatrist and three sessions of consultant psychiatrist time. An on call rota of junior doctors provides cover in the evenings and weekends.

Referrals were accepted if, based on the information received, the person appeared to be suffering from an acute mental illness potentially severe enough to warrant admission. Assessments seen as urgent were normally carried out within two hours of referral, usually in the patient's home.

Excluded from assessment were those under the age of 16, those referred specifically for inpatient detoxification or starting clozapine, and those with dementia. Following assessment, if the person was still seen as potentially requiring admission, home treatment was offered as an alternative if it appeared safe to do so. If neither CTT treatment or admission was warranted then the assessed person was referred on to the community mental health team for followup, or in some cases, back to the general practitioner.

Data concerning all those assessed were recorded, as to whether they were:

(a) seen as appropriate for home treatment and 'taken on' by the CTT

(b) admitted at the point of assessment

(c) admitted after the CTT had started to work with them and if so, why (in the opinion of the CTT staff involved in the admission).

ICD-10 diagnoses (World Health Organization, 1992) were recorded for all patients assessed. The $\chi^{2}$ test corrected for continuity assessed, if possible, the probability that the figures obtained were due to chance alone. Alpha levels were set at 0.05 . 
Table 1. Assessments and admissions

\begin{tabular}{|c|c|c|c|c|c|c|c|c|}
\hline $\begin{array}{l}\text { Diagnosis } \\
\text { (ICD-10 codes) }\end{array}$ & $\begin{array}{l}\text { Number } \\
\text { asesesed }\end{array}$ & $\begin{array}{l}\text { Percentage } \\
\text { of cliagnostic } \\
\text { category } \\
\text { 'taken on' } \\
\text { (n) }\end{array}$ & $\chi^{2}$ (d.f.) & $\boldsymbol{P}$ & $\begin{array}{l}\text { Percentoge } \\
\text { of category } \\
\text { admitted of } \\
\text { assessment } \\
\text { (n) }\end{array}$ & $\chi^{2}$ (d.f.) & $\mathbf{P}$ & $\begin{array}{l}\text { Percentage } \\
\text { of category } \\
\text { admitted } \\
\text { from CT (n) }\end{array}$ \\
\hline $\begin{array}{l}\text { Schizophrenia and other } \\
\text { psychoses }(20-29)\end{array}$ & 65 & $69.2(45)$ & $1.47(1)$ & $>0.05$ & $18.5(12)$ & $2.92(1)$ & $>0.05$ & $15.6(7)$ \\
\hline Mood disorders (30-39) & 142 & $74.6(106)$ & $16.59(1)$ & $<0.01$ & $7.0(10)$ & $6.10(1)$ & $<0.05$ & $18.9(20)$ \\
\hline $\begin{array}{l}\text { Neurotic, stress related and } \\
\text { somatoform disorders }(40-48)\end{array}$ & 31 & $67.7(21)$ & $0.25(1)$ & $>0.05$ & $0.0(0)$ & $3.63(1)$ & $>0.05$ & $4.8(1)$ \\
\hline $\begin{array}{l}\text { Disorders of adult personality } \\
\text { and behaviour }(60-69)\end{array}$ & 48 & 37.5 (18) & $15.58(1)$ & $<0.01$ & $25.0(12)$ & $8.35(1)$ & $<0.01$ & 22.2 (4) \\
\hline Other diagnoses & 32 & 21.9 (7) & $26.17(1)$ & $<0.01$ & & $0.51(1)$ & $>0.05$ & $0.0(0)$ \\
\hline All categories & 318 & 61.9 (197) & $45.48(4)$ & $<0.01$ & $11.6(37)$ & $18.46(4)$ & $<0.01$ & $16.2(32)$ \\
\hline
\end{tabular}

\section{Findings}

During the year 318 people were assessed and $61.9 \%$ were taken on by the CTT. Overall there was a strongly significant relationship between membership of a diagnostic category and likelihood of being taken on or not $(P<0.01)$. A diagnosis of mood disorder was linked with a significantly increased likelihood of being taken on $(P<0.01)$, while a diagnosis of schizophrenia or neurotic disorder showed an increased likelihood, but not significantly so. Other diagnoses, including personality disorder, were predictive of an increased likelihood of not being taken on $(P<0.01)$

Overall, diagnosis was found to have an association with the likelihood of admission, with mood disorders being significantly less likely to be admitted at assessment, and those diagnosed with personality disorder more likely to be admitted. Fifty per cent of those diagnosed with mood disorder who were admitted at the point of assessment were hypomanic, although only constituting $14.2 \%$ of the total number with mood disorders assessed. All those with an 'other' diagnosis who were admitted had alcohol-related problems.

For those admitted, both at the point of assessment and from the CTT, once being taken on for home treatment, the most common given reason was 'risk to self.

\section{Comment}

The results suggest that the CTT was able to work effectively in preventing hospital admission for the majority of referred people in all diagnostic categories, although there were some significant variations as to take on and admission rates between those categories.

Those with mood disorders were rarely admitted at the point of assessment, despite frequently presenting with suicidal ideation. This contrasts with relatively low take on and high admission rates for those with personality disorders, often due to persistent threats of selfharm despite offers of home treatment. Tyrer et al (1994) also found that personality disorder was linked with relatively poor outcomes in a community service (and relatively good ones in inpatient areas).

The results differ in some ways from those in other studies. Other services have had higher admission rates both at the point of assessment (Tufnell et al, 1985) and subsequently once receiving home treatment. Variations are also seen in the effectiveness of home treatment

Table 2. Reasons for admission

\begin{tabular}{|c|c|c|c|c|}
\hline Reason & $\begin{array}{l}\text { At assessment } \\
n\end{array}$ & $\%$ & $\begin{array}{l}\text { From } C \pi \\
n\end{array}$ & $\%$ \\
\hline Risk to self & 16 & 43.2 & 16 & 50.00 \\
\hline Refusal to comply with planned treatment & 3 & 8.1 & 2 & 6.25 \\
\hline Risk to others & 6 & 16.2 & 2 & 6.25 \\
\hline Patient preference for admission & 10 & 27.0 & 2 & 6.25 \\
\hline Carers unable to cope & 2 & 5.4 & 2 & 6.25 \\
\hline Did not improve despite $C \pi$ input & - & - & 5 & 15.60 \\
\hline Preplanned admission & - & _ & 3 & 9.40 \\
\hline
\end{tabular}

Diagnosis, assessments and admissions from a community treatment team 
services in preventing admission with different diagnostic categories (Fenton et al, 1982). Such variations may be due to a range of factors, such as variations in working practices, skill mix. referral patterns, availability of other community resources and accommodation, and the possibility of higher levels of disturbance in psychotic inner-city patients.

More detailed research is clearly required in order to investigate more precisely which behaviours and symptoms identified at assessment are predictive of future outcomes in terms of service provision; broad diagnostic categories being a blunt instrument in this regard.

\section{References}

Burns, T. BeArdsmore, A., Bhat, A. V., et al (1993) A controlled trial of home-based acute psychiatric services. I: Clinical and social outcome. British Journal of Psychiatry, 163, 49-54.

Dean, C.. Philups. J., Gadd, E., et al (1993) Comparison of community based service with hospital based service for people with acute. severe psychiatric illness. British Medical Journal, 307, 473-476.

Fenton, F., Tessier, L., Struening, E., et al (1982) Home and Hospital Psychiatric Treatment. London: Croom Helm.
Hoult, J., Rosen. A. \& ReYNolds, I. (1984) Community orientated treatment compared to psychiatric hospital orientated treatment. Social Science and Medicine, 8. 11. 1005-1010.

JoHNSON. S. (1997) London's Mental Health: A Report to the King's Fund Commission. London: King's Fund.

Mujien, M.. Marks, I. M. Connolly, J., et al (1992) The Daily Living Programme. Preliminary comparison of community versus hospital-based treatment for the seriously mentally ill facing emergency admission. British Journal of Psychiatry, 160, 379-384.

STEIN. L. I., TEST, M. A. \& MARX. A. J. (1975) Alternative to the hospital: a controlled study. American Joumal of Psychiatry, 132, 517-522.

TuFNEL. G., Bouras, N., WATSON. J. P.. et al (1985) Home assessment and treatment in a community psychiatric service. Acta Psychiatrica Scandinavica, 72, 20-28.

Tyrer. P.. MERson, S., ONYETt, S., et al (1994) The effect of personality disorder on clinical outcome. social networks and adjustment: a controlled clinical trial of psychiatric emergencies. Psychological Medicine, 24. 731-740.

WORLD HEALTH ORGaNization (1992) The Tenth Revision of the International Classification of Diseases and Related Health Problems (ICD-10). Geneva: WHO.

*Neil Brimblecombe, Team Leader, Dacorum Community Treatment Team, St Paul's, Slippers Hill, off Allandale, Hemel Hempstead, Herts HP2 5XY; and Geraldine H. O'Sullivan, Consultant Psychiatrist, Albany Lodge, St Albans, Herts

*Correspondence

\title{
Psychiatrists' attitudes to maintenance drug treatment in depression
}

\author{
Graham A. Jackson and Ishbel Maciver
}

\begin{abstract}
Aims and method The recurrence rate of major depression can be decreased by the use of maintenance drug treatment. This paper describes a survey of Scottish psychiatrists' attitudes to prescribing maintenance therapy. Questionnaires were sent to all Scottish psychiatrists at consultant and associate specialist grade.

Results It is evident that there are major differences in prescribing practices. How patients are managed would appear to depend on to whom they are referred. Clinical implications Psychiatrists do not appear to be practising evidence-based medicine in this context.
\end{abstract}

There is perhaps a need for greater consensus on the prevention of recurrence.

Until the late 1970 s, depression was generally described as an acute illness from which the patient was expected to return to a state of wellbeing. It was recognised that some individuals were prone to recurrent episodes, but it was felt that each of these should be treated as a discrete entity and that between these the individual would make a complete recovery. More recent 